\title{
Research Sguare \\ B- mode and Color Doppler sonographic appearance of pelvic tendon, ligament, and uterine blood flow in non-pregnant and heavy pregnant dairy cows
}

Ahmed Sharshar

University of Sadat City

Ahmed Elweza ( $\square$ ahmed.elweza@vet.usc.edu.eg )

University of Sadat City https://orcid.org/0000-0002-3108-2366

Shaaban Gadallah

University of Sadat City

Reda Rashed

University of Sadat City

Amal Hammad

University of Sadat City

Hamed Elbaz

University of Sadat City

\section{Research Article}

Keywords: Cow, Doppler, pelvic ligaments, pregnancy, tendon, middle uterine artery

Posted Date: July 26th, 2021

DOI: https://doi.org/10.21203/rs.3.rs-709954/v1

License: (c) (i) This work is licensed under a Creative Commons Attribution 4.0 International License.

Read Full License 


\section{Abstract}

The present study was carried out to provide comparative B-mode and Doppler ultrasonographic description of pelvic tendon, ligaments, middle uterine artery and placentom in non-pregnant and heavy pregnant cows. It is also, monitors pregnancy associated changes including hemodynamic parameters of middle uterine artery along with, serum estrogen and progesterone levels. Forty healthy pluiparous dairy cows of native breeds were used in this study. The animals were divided into two groups each contain 20 cows. The first one was non-pregnant and the second one was heavy pregnant at 9th month of gestation. The examination was carried out with multiple imaging B-mode and color Doppler ultrasonography. Pelvic tendon and ligaments including dorsal branch of the dorsal sacroiliac ligament- thoracolumbar fascia combination (D-DSIL-TLF), lateral and ventral branches of the dorsal sacroiliac ligament (L-DSIL and V-DSIL respectively), and sacrosciatic ligament (SSL) as well as the middle uterine artery (MUA) and placentome were examined. Serum estrogen and progesterone levels were also evaluated and compared between both groups. The obtained results revealed that pregnancy greatly influence doppler indices and diameter of MUA as well as serum estrogen and progesterone concentration besides, measurements of pelvic ligaments except for the thickness and cross -sectional area of D-DSIL- TLF combination. The obtained results can be used as a guide for future studies dealing with monitoring normal and abnormal pregnancy in cows.

\section{Introduction}

Dystocia and its consequences are a common problem in bovine breeding. It is frequently associated with high calf mortality rates and negatively impacts the subsequent pregnancies. It is also implicated in higher cow culling rate, lower fertility, reduced milk production, and great expenses of veterinary care services (Fourichon et al. 2000; Oliveira and Gheller 2009). There is an intimate relationship between ease of delivery and body conformation, pelvic shape and measurements and hormonal regulation of the dam in relation to calf birth weight besides its presentation and position (Naazie et al. 1989; Nogalski 2002; Mee et al. 2011). Parturition occurs as a result of interaction between endocrine, neuronal, and mechanical factors (Knobil and Neill 1994; Hafez and Hafez 2000). The secreted hormones particularly estrogen and progesterone were modulated throughout bovine pregnancy and were involved in expulsion of alive fetus (Kindahl et al. 2002).

Doppler ultrasound is a valuable tool in veterinary obstetrics. It has been used in evaluation of uterine blood flow in Simmenthal heifers (Heppelmann et al. 2013), discrepancy between normal pregnancy and uterine torsion in buffaloes (Devender et al. 2018). It has been used also, in differentiating between normal pregnancy and pyometra in bitches (Pati et al. 2019), distinction of compromised pregnancy in Bos indicus cows (Hassan et al. 2020), and assessing changes in ovarian and uterine perfusion during the puerperium (El - sherbiny et al. 2020).

During pregnancy, some functional and structural changes usually occur in the uterine vascular system based on fetal nutritional requirements. It includes certain hemodynamic changes to ensure adequate 
blood supply to the developing placenta/fetus (Ferrel 1991).

Evaluation of internal pelvic dimensions as well as pelvic structures including bones and joints has gained a lot of attention during the past few years (Nogalski 2002; Bennett et al. 2008; Oliveira and Gheller 2009; Sharshar et al. 2020). To our knowledge, little attention has been paid to pelvic ligaments and tendons despite their significance for normal delivery. Moreover, there is a limited data about blood flow indices and changes in middle uterine artery during late gestation period in dairy cows. Therefore, the present study aimed to investigate the ultrasonographic B-mode description of pelvic ligaments, tendon, middle uterine artery and placentom. It also aimed to provide a Doppler sonographic description of uterine blood flow in non-pregnant and heavy pregnant dairy cows. We hypothesized that, sonographic appearance of the studied structures would vary between pregnant and non-pregnant cows.

\section{li. Materials And Methods}

\section{II-1-Ethical statement}

This study was approved by institutional Animal Care and Welfare Committee of Faculty of Veterinary Medicine, University of Sadat City, Egypt.

\section{II-2-Animals and study design}

The present study was conducted on a total number of 40 pluiparous healthy dairy cows of native breed (Baladi breed) belonging to the educational farm of the Faculty of Veterinary Medicine, University of Sadat City, Egypt, during the period from November to December 2020. The mean age was 7 years (range: 5 to 9 years) and mean body weight was $400 \mathrm{~kg}$ (range: 375 to $450 \mathrm{~kg}$ ) and the body condition score of the studied cows ranged from ( 3.5 to 4 ) on a scale of 5 . Cows were divided into two groups each contain 20 cows depending on the reproductive state. The $1^{\text {st }}$ group was non-pregnant and the $2^{\text {nd }}$ one was heavy pregnant at $9^{\text {th }}$ month of gestation. Animals were selected after breeding soundness examination and were proved to be free from any reproductive problems. All animals were apparently normal, vaccinated, and dewormed. The animals were kept under similar managemental conditions and housed in free stall barn and fed a balanced ration composed of Tibn and pelleted concentrates as well as green fodders (Berseem). They also allowed free access to water.

\section{II-3- Assessments}

\section{II-3-1-B-mode ultrasonographic examination of pelvic ligaments and tendon}

Ultrasonographic examination was carried out using ultrasonographic unit (Esaote MyLab ${ }^{\text {TM }}$ One VET, Italy) equipped with 6.6 to $18 \mathrm{MHz}$ micro-convex, linear array tendon and rectal linear probes. The examined animals were controlled in a stanchion and the hair overlaying the pelvis was clipped followed by cleaning, drying of the skin and spreading the ultrasonographic gel. Evacuation of feces from the rectum was performed immediately before transrectal examination. 
Pelvic ligaments including dorsal branch of the dorsal sacroiliac ligament (D-DSIL), lateral branch of the dorsal sacroiliac ligament (L-DSIL) and Sacrosciatic ligament (SSL), as well as pelvic tendon including thoracolumbar fascia (TLF) were examined using B-mode. Ultrasonographic images were obtained via longitudinal and transverse sections for each structure. Probe type and placement adopted frequency and depth, and the assessed variables for each examine structure are summarized in Tables 1 . The examination procedure followed the principles previously established by (Head 2014; Whitcomb and Vaughan 2015; Sharshar et al. 2020).

Table 1. The examined structures, probe type, the used frequency and depth, placement of the probe and the assessed variables.

\begin{tabular}{|c|c|c|c|c|c|}
\hline Examined structures & $\begin{array}{l}\text { Probe } \\
\text { type }\end{array}$ & Frequency & Depth & Placement of the probe & $\begin{array}{l}\text { Assessed } \\
\text { variables }\end{array}$ \\
\hline $\begin{array}{l}\text { Dorsal branch of the } \\
\text { dorsal sacroiliac } \\
\text { ligament- } \\
\text { thoracolumbar fascia } \\
\text { combination (D-DSIL- } \\
\text { TLF) }\end{array}$ & $\begin{array}{l}\text { Linear } \\
\text { tendon }\end{array}$ & $10 \mathrm{MHz}$ & $4 \mathrm{~cm}$ & $\begin{array}{l}\text { At the proximal part of } \\
\text { sacral tuber }\end{array}$ & $\begin{array}{l}\text { Shape, } \\
\text { echogenicity, } \\
\text { cross } \\
\text { sectional } \\
\text { area and } \\
\text { thickness }\end{array}$ \\
\hline $\begin{array}{l}\text { Lateral branch of the } \\
\text { dorsal sacroiliac } \\
\text { ligament (L-DSIL) }\end{array}$ & $\begin{array}{l}\text { Linear } \\
\text { tendon } \\
\text { or } \\
\text { Micro- } \\
\text { convex }\end{array}$ & $8 \mathrm{MHz}$ & $\begin{array}{l}10 \\
\mathrm{~cm}\end{array}$ & $\begin{array}{l}\text { The probe } \\
\text { was moved laterally in } \\
\text { a caudo-ventral } \\
\text { direction starting at the } \\
\text { caudal portion of the } \\
\text { sacral tuber }\end{array}$ & $\begin{array}{l}\text { Shape, } \\
\text { echogenicity, } \\
\text { and } \\
\text { thickness. }\end{array}$ \\
\hline $\begin{array}{l}\text { Sacrosciatic ligament } \\
\text { (SSL) }\end{array}$ & $\begin{array}{l}\text { linear } \\
\text { tendon } \\
\text { or } \\
\text { Micro- } \\
\text { convex }\end{array}$ & $10 \mathrm{MHz}$ & $7 \mathrm{~cm}$ & $\begin{array}{l}\text { The probe was placed } \\
\text { at its origin at the lateral } \\
\text { aspect of the sacral } \\
\text { transverse processes } \\
\text { and directed caudo- } \\
\text { ventrally to its insertion } \\
\text { at ischial tuber }\end{array}$ & $\begin{array}{l}\text { Shape, } \\
\text { echogenicity, } \\
\text { and } \\
\text { thickness }\end{array}$ \\
\hline $\begin{array}{l}\text { Ventral branch of the } \\
\text { dorsal sacroiliac } \\
\text { ligament (V-DSIL) }\end{array}$ & $\begin{array}{l}\text { Linear } \\
\text { tendon } \\
\text { or } \\
\text { Micro- } \\
\text { convex }\end{array}$ & $10 \mathrm{MHz}$ & $7 \mathrm{~cm}$ & $\begin{array}{l}\text { Probe was placed } \\
\text { transrectally }\end{array}$ & $\begin{array}{l}\text { Shape, } \\
\text { echogenicity, } \\
\text { and } \\
\text { thickness. }\end{array}$ \\
\hline
\end{tabular}

\section{II-3-2-B-mode and Doppler ultrasonographic examination of middle uterine artery and placentom}

The examination was carried out on the same basis as previously described by (Varughese et al. 2013; Elsherbiny et al. 2020; Hassan et al. 2020). A rectal spectral-wave Doppler ultrasound equipped with 10 $\mathrm{MHz}$ linear-array transrectal transducer (Esaote MyLab ${ }^{\mathrm{TM}}$ One VET, Italy) was used to examine the middle 
uterine artery, and placentom by the aid of color and spectral modes. The cross-sectional diameters of the middle uterine artery and placentom $(\mathrm{mm})$ were determined. The parameters used to assess blood flow were determined using automatic options on the device and the image was stored. The same analyzer traced the Doppler indices pulsatility index $(\mathrm{PI})$ and resistance index (RI).

\section{II-3-3-Assessment of estrogen and progesterone serum level}

Blood samples $(5 \mathrm{ml})$ were collected from the jugular vein of all cows. Samples were reserved in a slope direction for $12 \mathrm{~h}$ in the refrigerator, clotted samples were centrifuged for 15 minutes at $3000 \mathrm{rpm}$ and the collected serum was stored at $-20^{\circ} \mathrm{C}$ in Eppendorf tubes until analyzed. Serum concentration of Estrogen and progesterone was measured in the collected serum samples using ELISA kits (Calbiotech, Austin, Springer valley, CA, 91978, USA) following the micro-well method and the OD (optical density) absorbance has been adjusted at $450 \pm 10 \mathrm{~nm}$.

\section{II-4-Statistical analysis}

Statistical analysis was performed with GraphPad Prism 5 software (GraphPad Software Inc., La Jolla, CA, USA). The measured variables were compared among pregnant and non-pregnant animals using Independent Samples $t$-Test. Data are presented as mean \pm standard error (SE). The level of significance was set at $P<0.05$.

\section{lii. Results}

The dorsal branch of the dorsal sacroiliac ligament-thoracolumbar fascia combination appeared during transverse scan as curvilinear echogenic structure divided into two parts the lateral part representing the dorsal branch of the dorsal sacroiliac ligament which appear slightly echogenic convex structure covering the hyperechoic sacral tuber. The medial branch appears as V-shape echogenic structure extended medially to the proximal aspect of the dorsal spinous process of the first sacral vertebrae (Fig. 1A). In longitudinal scanning, both structures appeared as echogenic layer extended cranio-caudally covering sacral tuber. It divided into two echogenic layers at the cranial edge of the sacral tuber while proceeding caudally as a single cord like structure (Fig. 1B). The thickness of D-DSIL-TLF was $3.65 \pm 0.03 \mathrm{~mm}$ in pregnant cows and $3.69 \pm 0.02 \mathrm{~mm}$ in non-pregnant ones without significant difference between them (Fig. 2A). The mean cross-sectional area of both structures in pregnant cows was $1.36 \pm 0.02 \mathrm{~cm}^{2}$ while in non-pregnant cows was $1.4 \pm 0.01 \mathrm{~cm}^{2}$ with no significant difference between them (Fig. 2B). The LDSIL appeared in both pregnant and non-pregnant cows as linear echogenic structure extended caudolaterally in a slightly ventral direction to insert at the lateral aspect of the sacral crest which appears as hyperechoic arch (Fig. 1C). Its thickness was significantly lower in pregnant ( $3.24 \pm 0.37 \mathrm{~mm}$ ) compared to non-pregnant ( $5.36 \pm 0.33 \mathrm{~mm}$ ) ones (Fig. 2C). During longitudinal scan of SSL, appeared in both pregnant and non-pregnant cows as echogenic flat sheet interspersed with an-echoic areas. It is originating from a hyperechoic linear structure representing the lateral aspect of the sacral transverse process (Fig. 1D) and extending caudo-ventrally to insert at the Ischiatic tuber which appears as hyper 
echoic curvilinear structure (Fig. 3A). The thickness of SSL was significantly lower in pregnant $(6.32 \pm 0.2$ $\mathrm{mm}$ ) compared to non-pregnant $(8.14 \pm 0.29 \mathrm{~mm}$ ) cows (Fig. 2D). In longitudinal scan, the V-DSIL appeared as hyperechoic sheet joining between two smooth hyperechoic arches representing the iliac wing and the first sacral transverse process and pounded the sacroiliac joint ventrally (Fig. 3B). Its thickness was also significantly lower in pregnant $(2.7 \pm 0.31 \mathrm{~mm})$ than non-pregnant $(3.77 \pm 0.07 \mathrm{~mm})$ cows (Fig. 4A).

(B): Longitudinal sonogram at the dorsal aspect of sacral tuber (ST) of the same cow in Fig. 1A showing; the dorsal aspect of the dorsal sacroiliac ligament (D-DSIL), thoracolumbar fascia (TLF). D: dorsal direction. V: ventral direction. CR: cranial direction. CA: caudal direction

(C): Longitudinal sonogram of the lateral branch of the dorsal sacroiliac ligament (L-DSIL) (8 MHz microconvex probe, $10 \mathrm{~cm}$ depth) of 7 years old non-pregnant cow (LSC) lateral sacral crest. LAT: lateral direction. MED: medial direction. D: dorsal direction. V: ventral direction.

(D): Longitudinal sonogram of the sacro-sciatic ligament (SSL) at its origin (10 MHz linear tendon probe, $7 \mathrm{~cm}$ depth) of 9 years old non-pregnant cow. (STP) sacral transverse process. (L) lateral, (M) medial, (CA-V) caudo-ventral, (CR-D) cranio-dorsal

\section{Characterization and hemodynamic changes of uterine blood flow}

Regarding uterine blood flow, during rectal palpation by hand there was a characteristic change in the pulse wave of middle uterine artery (fremitus) in heavy pregnant than non-pregnant dairy cows. Scanning B-mode and Doppler sonography of blood flow of middle uterine artery of non-pregnant dairy cows revealed its small diameter $(0.82 \pm 0.02 \mathrm{~cm})$ and the existing low systolic velocity (Fig. 3C \&D\& 4B). On the other hand, there was a significant increase in the diameter $(1.54 \pm 0.1 \mathrm{~cm})$ of MUA with peak systolic velocity waveform of its blood flow with higher blood perfusion (represented by the bright orange pixels on the center of the artery) in heavy pregnant cows (Fig. 5A \&B \&4B). The Doppler indices (PI and RI), were significantly lower in heavy pregnant $(1.5 \pm 0.04$ and $0.63 \pm 0.03$ respectively) compared to nonpregnant ( $2.26 \pm 0.06$ and $0.91 \pm 0.01$ respectively) cows

\section{Characterization and hemodynamic changes of placentom}

The placentom of the gravid horn showed a moderate blood perfusion as evidenced by bright orange pixels on the center of the placentom (Fig. 5C \&D). The blood flow pattern of placentom exhibited both the systolic and diastolic peaks using color doppler.

Serum estrogen concentration was significantly higher in heavy pregnant $(170 \pm 3.5 \mathrm{Pg} / \mathrm{ml})$ cows compared to non-pregnant $(7.5 \pm 0.67 \mathrm{Pg} / \mathrm{ml})$ ones without. Serum progesterone concentration showed slight increase in heavy pregnant cows than non-pregnant ones with no significance difference $(5.14 \pm$ 0.67 and $3.35 \pm 0.89 \mathrm{ng} / \mathrm{ml}$ ) between them (Fig. 6A\&B). 


\section{Iv. Discussion}

Ruminant pelvis is a multiple functional osteoligamentous complex structure (Oliveira et al. 2003; Silva et al. 2019). It encircles the birth canal as an osseous ring and limit its expansion (Tyczka 1998). As a result of contentious breeding with the general trend to increase body and udder mass, pelvic structure is usually subjected to multiple undesirable changes (Jalakas et al. 2000; Bennett et al. 2008). Subsequently, bovine pelvis would become increasingly unsuitable for normal delivery (Duce et al. 2002; Nahkur et al. 2003). During reproductive cycle, there is increasing load and stress upon the supporting tissues of the reproductive organs due to the concomitant changes in their weight and size (Oliveira and Gheller 2009; Majida et al. 2010; Hopper 2014; Herring 2014). pelvic structure and dimensions of cows has gained a lot of attention during the past 30 years to predict those at higher risk of dystocia (Laster1974; Johnson et al. 1988).

In adult cow the hip bones are joined osseously, and the pelvic symphysis is ventrally reinforced by the symphysial crest. Therefore, the pelvic cavity can be widened at the time of delivery by relaxation of the sacroiliac joint and the broad sacro-ischiatic ligament (Jalakas and Saks 2001). Our results showed that the thickness of the lateral and the ventral branches of the dorsal sacroiliac ligament and the SSL were significantly lower in heavy pregnant cows than non-pregnant ones. This may be attributed to alteration of ligaments structure as a result of increasing the level of the circulating hormones particularly estrogen and progesterone at the last trimester of gestation (Henricks et al. 1972; Derivaux and Ectors 1984; Kindahl et al. 2002). In authors opinion, reduction of pelvic ligaments thickness could be also an indicative for its possible relaxation because of proximity of delivery with subsequent widening of the sacroiliac joint and increments of pelvic width at its inlet and outlet respectively (Jalakas and Saks 2001).

To our knowledge this may be the first report provided complete ultrasonographic description of pelvic ligaments and tendon in heavy pregnant and non-pregnant cows. Only Sharshar et al. (2020) described some of them, but not all including D-DSIL- TLF combination and L-DSIL. According to this study, the DDSIL- TLF combination and L-DSIL appeared as moderately echogenic curvilinear or linear structure, respectively. This found in accordance with previously published reports in equine (Engeli et al. 2006; Sharshar et al. 2018) and cattle (Sharshar et al. 2020). The SSL appeared at its origin as moderately echogenic sheet interspersed with small anechoic areas. This may be attributed to its anatomical configuration in which the ligament attached to more than one structure at its origin occluding the last sacral and coccygeal vertebrae (Nahkur et al. 2003). In the current work, the thickness of both D-DSIL-TLF and L-DSIL was estimated in heavy pregnant and non-pregnant cows. Our results found in accordance with previously published data (Sharshar et al. 2020).

Transrectal Doppler sonography was proved to be a valuable non-invasive technique to assess the uterine blood flow during pregnancy in buffaloes and asses hemodynamic changes in abnormal pregnancy (e.g. abnormalities in uterine blood flow/placenta/fetus) and its extent of deviation from normal pregnancy 
(Varughese et al. 2013). In the present study, it was efficient in determining and comparing the uterine blood flow in heavy pregnant and non-pregnant cows.

In the present study, Scanning B-mode and Doppler sonography of blood flow of middle uterine artery of non-pregnant dairy cows revealed small diameter of MUA and low systolic velocity. This finding agrees with previous study in cows (El-sherbiny et al. 2020) in which diameter of ovarian and uterine arteries gradually declined from the 1 st week till the end of 6 th week after calving. In the same way, the uterine perfusion was significantly decreased at the 1st week postpartum in dairy cows (Krueger et al. 2009; Heppelmann et al. 2013).

Here, we reported a significant increase in the diameter of middle uterine artery and peak systolic velocity waveform of its blood flow in heavy pregnant cows. These findings were in harmony with Hassan et al. (2020) who reported an increment in the diameter of uterine artery and blood flow as pregnancy advances. Based on both studies along with the demonstrated reduction of blood flow in the middle uterine artery in case of uterine torsion in cattle (Singh et al. 2016; Devender et al. 2018), it can be elucidated that increased blood flow of middle uterine artery is a characteristic doppler finding for pregnancy.

The placentom of the gravid horn showed moderate blood perfusion represented by the bright orange pixels on the center of the placentom. These results were parallel to that previously recorded by Hassan et al (2020). Therefore, fetal and maternal environment were indispensable factors for the maintenance of successful pregnancy (Spencer et al. 2006).

In the present study, there was a significant difference between heavy pregnant and non-pregnant dairy cows in the measured Doppler indices (PI and RI). Similar results were obtained by (Varughese et al. 2013; Singh et al. 2017; Hassan et al. 2020). The obtained PI and RI values were significantly lower in heavy pregnant than non-pregnant cows. These findings could be indicative for reduced resistance to blood flow as well as better uterine perfusion as a result of pregnancy (Silva 2011). In agreement with our findings, in the study of Bollwein et al. (2002), the PI and RI parameters were decreased continuously during the first 8-month of gestation. On the other hand, in another study (Panarace et al. 2006), significant changes in PI and RI were not detected after 26th week of gestation in cows. This discrepancy might be attributed to fetal, cellular, hormonal, nutritional and molecular changes that predispose to different hemodynamic patterns during late pregnancy in cows, which need future studies.

\section{Conclusion}

This study elucidated the clinical applicability of ultrasound in determining pregnancy associated changes in pelvic ligaments whereas thickness. the present study could be also a valuable tool to ascertain base line data of uterine hemodynamic changes (PI and RI) and diameter of MUA in late pregnancy in correlation with non-pregnant dairy cows. It also, provided information about the hormonal profile during late gestation period in cows. These findings could be useful for dam and fetus before 
further obstetrical handling that can be evaluated by trans-rectal color Doppler sonography. Further study is needed to evaluate such B-mode and Doppler data in cows delivered normally and that with dystocia.

\section{Declarations}

\section{Statement of contribution}

A. Sharshar, A. Elweza and H. Elbaz shared experimental design, data analysis and clinical activities. R. Rashed, S. Gadallah and A. Hammad participated in manuscript writing, reviewing and editing.

\section{Funding}

The present work did not receive any specific fund.

\section{Conflict of interest}

The authors declare that no conflict of interest exists.

\section{Data Availability Statement}

The data supporting the findings of the present study are available by the corresponding author upon request.

\section{Ethical approval}

All appropriate national and international guidelines for the care and use of animals were followed.

\section{Consent to participate}

All authors participated freely in the research.

\section{Consent for publication}

All authors read and approved the final manuscript.

\section{References}

1. Bennett GL, Thallman RM, Snelling WM, Kuehn LA (2008) Experimental selection for calving ease and postnatal growth in seven cattle populations. II. Phenotypic differences. J Anim Sci 86:21032114

2. Bollwein H, Baumgartner U, Stolla R (2002) Transrectal Doppler sonography of uterine blood flow in cows during pregnancy. Theriogenology 57:2053-2061

3. Devender, Chandolia RK, Singh G, Pandey AK, Kumari S (2018) ) Evaluation of blood flow in middle uterine artery by color doppler ultrasonography in uterine torsion buffaloes before and after 
detorsion. Buffalo Bull 37(4):495-502

4. Duce KM, Sack WO, Wensing CI (2002) Textbook of Veterinary Anatomy, 3. Saunders Company, rd edn. Philadelphia

5. El-sherbiny $\mathrm{H}$, El-shahat $\mathrm{KH}$, Abo El-maaty AM, Abdelnaby EA (2020) Ovarian and uterine haemodynamics and their relation to steroid hormonal levels in postpartum Egyptian buffaloes. Bulg J Vet Med. DOI:10.15547/bjvm.2020-0091

6. Ferrel CL (1991) Maternal and fetal influences on uterine and conceptus development in the cow II. Blood flow and nutrient flux. J Anim Sci 69:1954-1965

7. Fourichon C, Seegers H, Malher X (2000) Effect of disease on reproducelon in the dairy cow. rnetaanalysis Theriogenology 53:1729-1759

8. Hafez ESE, Hafez B (2000) Reproduction in Farm Animals, 7th edn. Lippincott Williams and Wilkins, Philadelphia, 509p. http://dx.doi.org/10.1002/9781119265306

9. Hassan M, Arshad U, Erdoğan G, Ahmad N (2020) Evaluation of haemodynamic changes of uterine arteries using Doppler ultrasonography during different stages of pregnancy in Bos indicus cows. Reprod Dom Anim 55:1425-1433

10. Head M (2014) Ultrasonography of the pelvis. In: J.A. Kidd, K. G. Lu, M. L. Frazer (eds), Atlas of Equine Ultrasonography. John Wiley and Sons, Ltd, Chichester, West Sussex, UK. 1st edition. pp. 183-197. https://doi.org/10.1002/9781118798119.ch8

11. Henricks DM, Dickey JF, Hill JR, Johnston WE (1972) Plasma Estrogen and Progesterone Levels After Mating, and During Late Pregnancy and Postpartum in Cows. Endocrinol 90(5):1336-1342

12. Heppelmann M, Krüger L, Leidl S, Bollwein H (2013) Transrectal Doppler sonography of uterine blood flow during the first two weeks after parturition in Simmenthal heifers. J Vet Sci 14(3):323-327

13. Herring AD (2014) Beef cattle production systems. CABI, USA

14. Hopper RM (2014) Bovine reproduction. Wiley, USA

15. Jalakas M, Saks P (2001) Morphology and Ossification of Pelvic Symphysis in the Cow and its impact on Dystocia. Eesti Loomaarstide Ühing, Veterinaarmeditsiin Tartu, pp 35-47

16. Jalakas M, Saks P, Klaassen M (2000) Suspensory Appara-tus of the Bovine Udder in the Estonian Black and White Holstein Breed: Increased Milk Production (Udder Mass) Induced Changes in the Pelvic Structure. Anat Histol Embryol J Vet Med 29:51-61

17. Johnson SK, Deutscher GH, Parkhurst A (1988) Relationship of pelvic srructure, body rneasurements, pelvic area and calving difficulty. J Anim Sci 66:1081-1088

18. Kindahl H, Kornmatitsuk B, Königsson K, Gustafsson H (2002) ) Endocrine changes in late bovine pregnancy with special emphasis on fetal well-being. Domest Anim Endocrinol 23(1-2):321-328

19. Knobil E, Neill JD (1994) The Physiology of Reproduction, 2nd edn. Raven Press, New York, 1372p

20. Krueger L, Koerte J, Tsousis G, Herzog K, Flachowsky G, Bollwein H (2009) Transrectal Doppler sonography of uterine blood flow during the first 12 weeks after parturition in healthy dairy cows. Anim Reprod Sci 114:23-31 
21. Laster DB (1974) Factors affecting pelvic size and dystocia in beef cattle. J Anim Sci 38:496-503

22. Majida M, Braekken IH, Bø K, Benth JS, Engh ME (2010) Validation of three dimensional perineal ultrasound and magnetic resonance imaging measurements of the pubovisceral muscle at rest. Ultrasound Obstet Gynecol 35:715-722

23. Mee JF, Berry DP, Cromie AR (2011) Risk factors for calving assistance and dystocia in pasture-based Holstein-Friesian heifers and cows in Ireland. Vet J 187:189-194

24. Naazie A, Makarechian MM, Berg RT (1989) Factors influencing calving difficulty in beef heifers. J Anim Sci 67:3243-3249

25. Nahkur E, Jalakas M, Andrianov V, Ernits E, Järv E (2003) A Comparative Anatomical Study Of The Pelvis in the Contemporary and Medieval Cow and Elk. Veterinarija IR Zootechnika T 24(46):40-44

26. Oliveira LF, Gheller VA (2009) Evaluation of internal pelvic measurements of Holstein cattle from Minas Gerais in Brazil. Ciênc Anim Brasil (Suppl 1) VIII Congr Buiatr Anais: 802-807

27. Oliveira PC, Bombonato PP, Balieiro JCC (2003) Pelvimetria em vacas Nellore. Brazilian J Vet Res Anim Sci 40(4):297-304. http://dx.doi.org/10.1590/S1413-95962003000400009

28. Panarace M, Garnil C, Marfil M, Jauregui G, Lagioia J, Luther E, Medina M (2006) Trans-rectal sonography for evaluation of uterine blood flow throughout pregnancy in 13 Cows. Theriogenology 66(9):2113-2119

29. Pati P, Mishra PC, Patra BK, Jena B (2019) Hemodynamic Changes in Uterine Artery during Pyometra in Bitches. Int J Curr Microbiol App Sci 8(5):381-385

30. Sharshar A, El-Sunsafty M, Misk T, Gadallah S, Fade M (2018) Comparative ultrasonographic characterization of the pelvis in clinically normal horses and donkeys. VETERINARSKI ARHIV 88(5):607-625

31. Sharshar A, Gadallah S, Elsunsafty M, Fadel M (2020) The Pelvic Girdle of Cow: Ultrasonographic Description. Advan Anim Vet Sci 8(2):190-197

32. Silva RLS, Oliveira WDC, Daniel Biagiotti D, Guilherme José BC, Ferreira GJ (2019) Pelvimetry of multiparous Nellore cows in the cycling and early puerperal stages. Pesq Vet Bras 39(5):348-354

33. Silva LA (2011) Local effect of the conceptus on uterine vascular perfusion and remodeling during early pregnancy in mares - New findings by Doppler ultrasonography. Acta Sci Vet 39(1):123-134

34. Singh G, Chandolia RK, Dutt R, Saini A, Malik RK (2017) Characterization of middle uterine artery and fetal umbilical blood flow in pregnant murrah buffalo. Ind J Anim Reprod 39(1):11-14

35. Singh N, Ghuman SS, Gandotra VK (2016) Predicting the Impact of Degree and Duration of Uterine Torsion on Uterine Blood Supply in Cattle using Doppler Ultrasonography. J Anim Res 6(4): 685-689

36. Spencer TE, Johnson GA, Bazer FW, Burghardt RC, Palmarini M (2006) Pregnancy recognition and conceptus implantation in domestic ruminants: Roles of progesterone, interferons and endogenous retroviruses. Reprod Fertil Develop 19:65-78

37. Whitcomb MB, Vaughan B (2015) Ultrasonographic evaluation of the coxofemoral joint. Proceedings of the 61st annual convention of the American association of equine practitioners, December (2015), 
Las Vegas, Nevada, USA. pp. 346-354

\section{Figures}
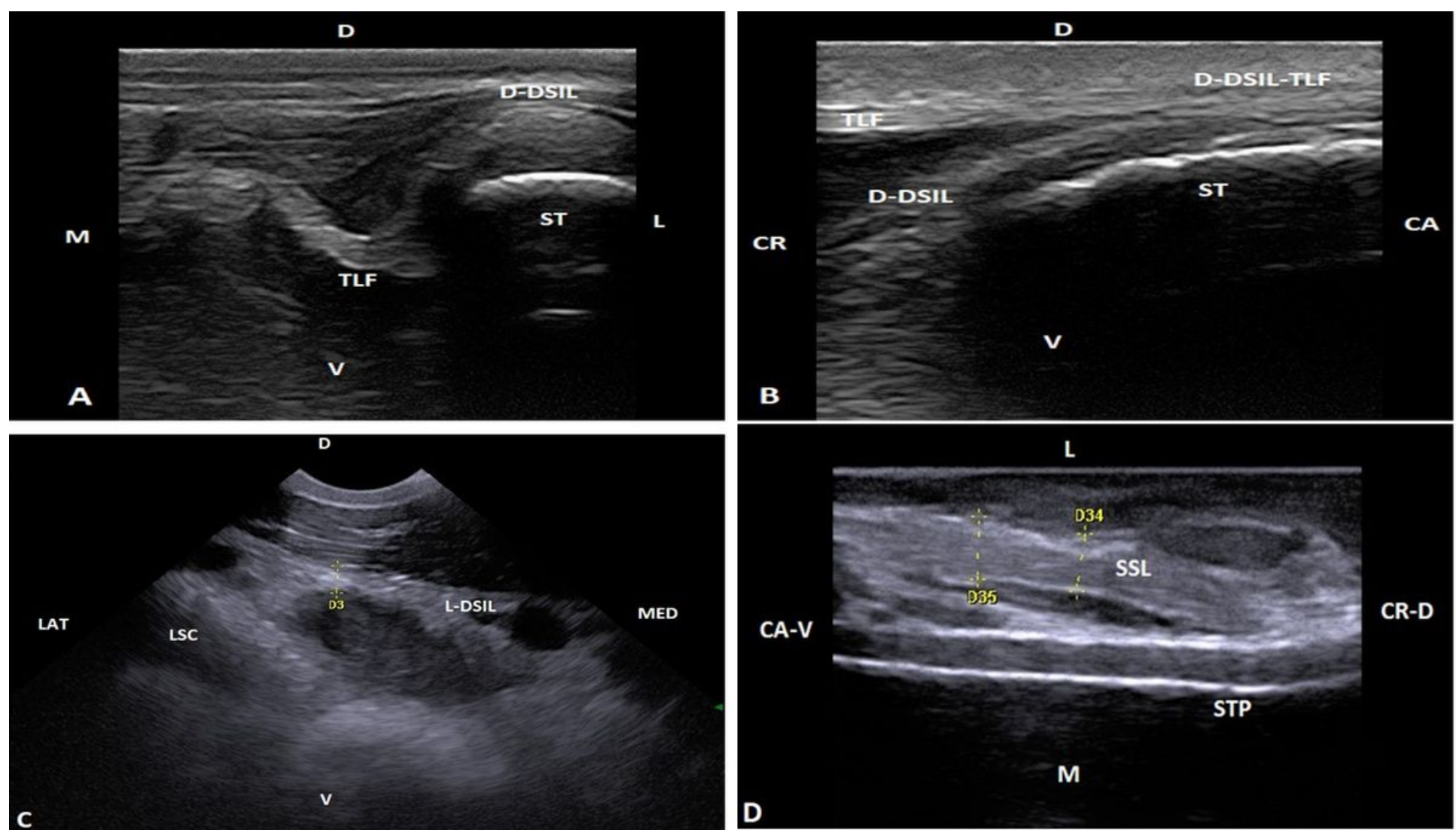

\section{Figure 1}

(A): Transverse sonogram of the dorsal sacroiliac region (linear tendon probe, $10 \mathrm{MHz}$ and $4 \mathrm{~cm}$ depth) of 7 years old pregnant cow. The dorsal branch of the dorsal sacroiliac ligament (D-DSIL), sacral tuber (TS), thoracolumbar fascia (TLF), D: dorsal direction. V: ventral direction. M: medial. L: lateral. (B): Longitudinal sonogram at the dorsal aspect of sacral tuber (ST) of the same cow in figure 1A showing; the dorsal aspect of the dorsal sacroiliac ligament (D-DSIL), thoracolumbar fascia (TLF). D: dorsal direction. V: ventral direction. CR: cranial direction. CA: caudal direction (C): Longitudinal sonogram of the lateral branch of the dorsal sacroiliac ligament (L-DSIL) (8 MHz micro-convex probe, $10 \mathrm{~cm}$ depth) of 7 years old non-pregnant cow (LSC) lateral sacral crest. LAT: lateral direction. MED: medial direction. D: dorsal direction. V: ventral direction. (D): Longitudinal sonogram of the sacro-sciatic ligament (SSL) at its origin (10 MHz linear tendon probe, $7 \mathrm{~cm}$ depth) of 9 years old non-pregnant cow. (STP) sacral transverse process. (L) lateral, (M) medial, (CA-V) caudo-ventral, (CR-D) cranio-dorsal 

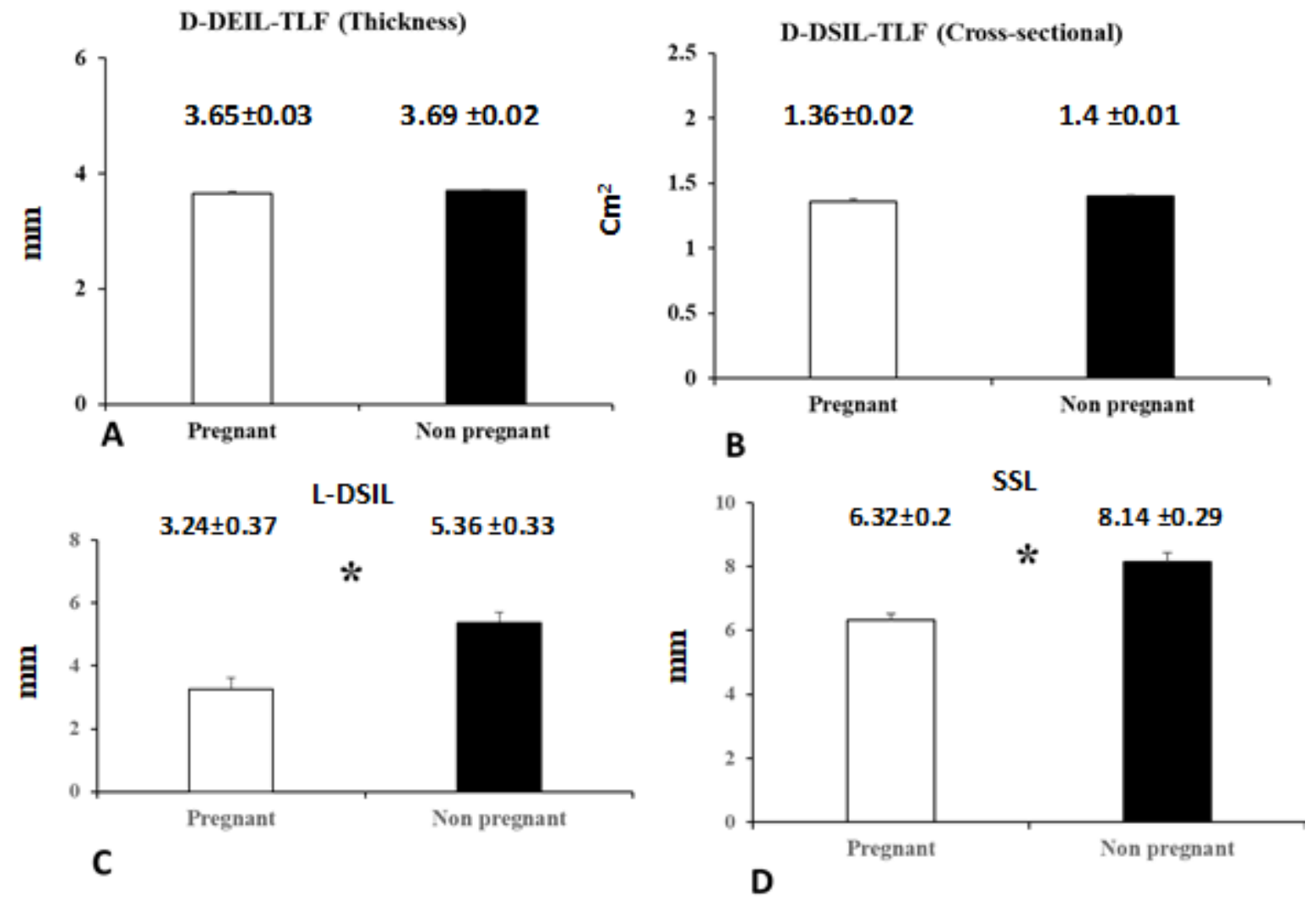

Figure 2

(A \&B): mean thickness and cross-sectional area of dorsal branch of the dorsal sacroiliac ligamentthoracolumbar fascia combination (D-DSIL-TLF) in pregnant and non-pregnant cows; (C): Thickness of the lateral branch of the dorsal sacroiliac ligament (L-DSIL) in pregnant and non-pregnant cows; (D): mean thickness of the sacrosciatic ligament (SSL) in pregnant and non-pregnant cows. All data are presented as mean $\pm S E$. *Values are significantly different between pregnant and non-pregnant cows. 

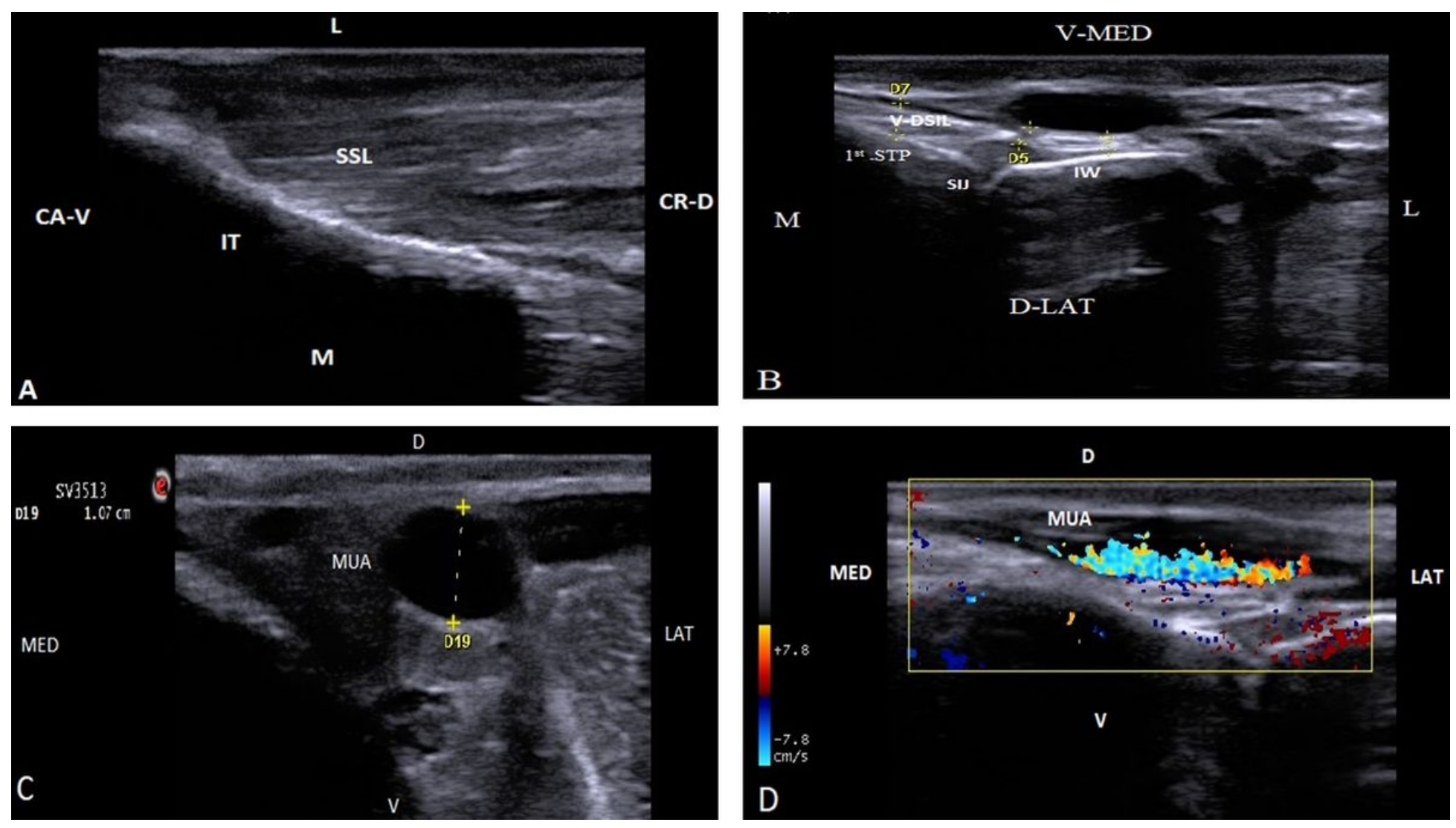

\section{Figure 3}

(A): Longitudinal sonogram of the sacro-ischiatic ligament at its insertion (SSL) of the same animal in Figure 1D. (IT) ischial tuber. (L) lateral, (M) medial, (CA-V) caudo-ventral, (CR-D) cranio-dorsal; (B): Longitudinal sonogram of the ventral branch of the dorsal sacroiliac ligament (V-DSIL) of 5 years old non -pregnant cow. (IW) iliac wing, (1st STP) sacral transverse process of the first sacral process, (SIJ) sacroiliac joint, (V-MED) ventro-medial, (D-LAT) dorsolateral ;(C \&D): Ultrasonographic monitoring of middle uterine artery of non-pregnant cows. (C): B-mode ultrasonography; (D): Doppler sonography. 
VDSIL
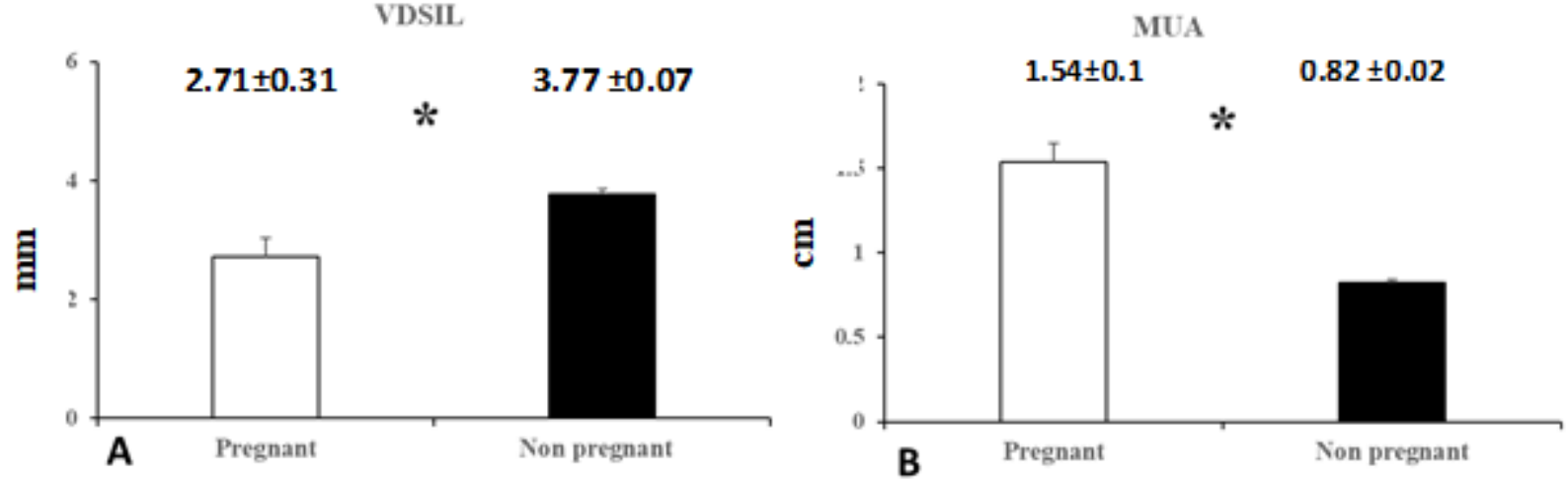

PI
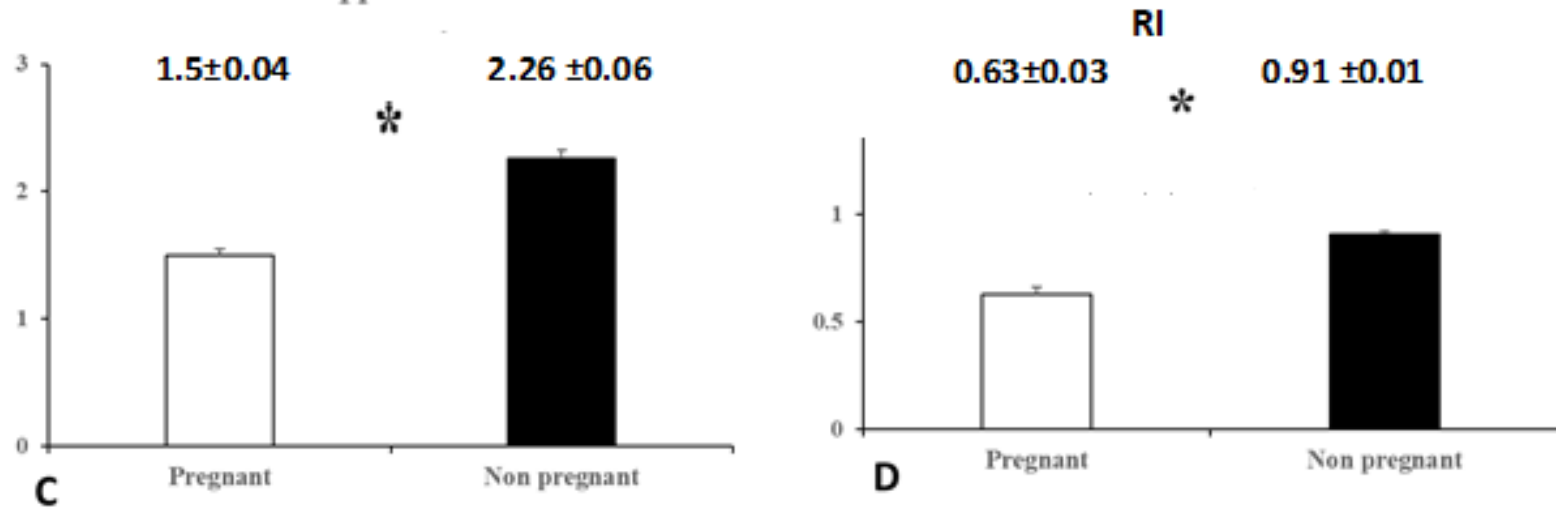

Figure 4

(A): mean thickness of the ventral branch of the dorsal sacroiliac ligament (V-DSIL) in heavy pregnant and non-pregnant cows; (B): mean diameter of the middle uterine artery (MUA) in heavy pregnant and non-pregnant cows; (C \&D): Pulsatility index (PI) and resistance index (RI) in heavy pregnant and nonpregnant dairy cows. Data are presented as mean \pm SE. *Values are significantly different between pregnant and non-pregnant cows 

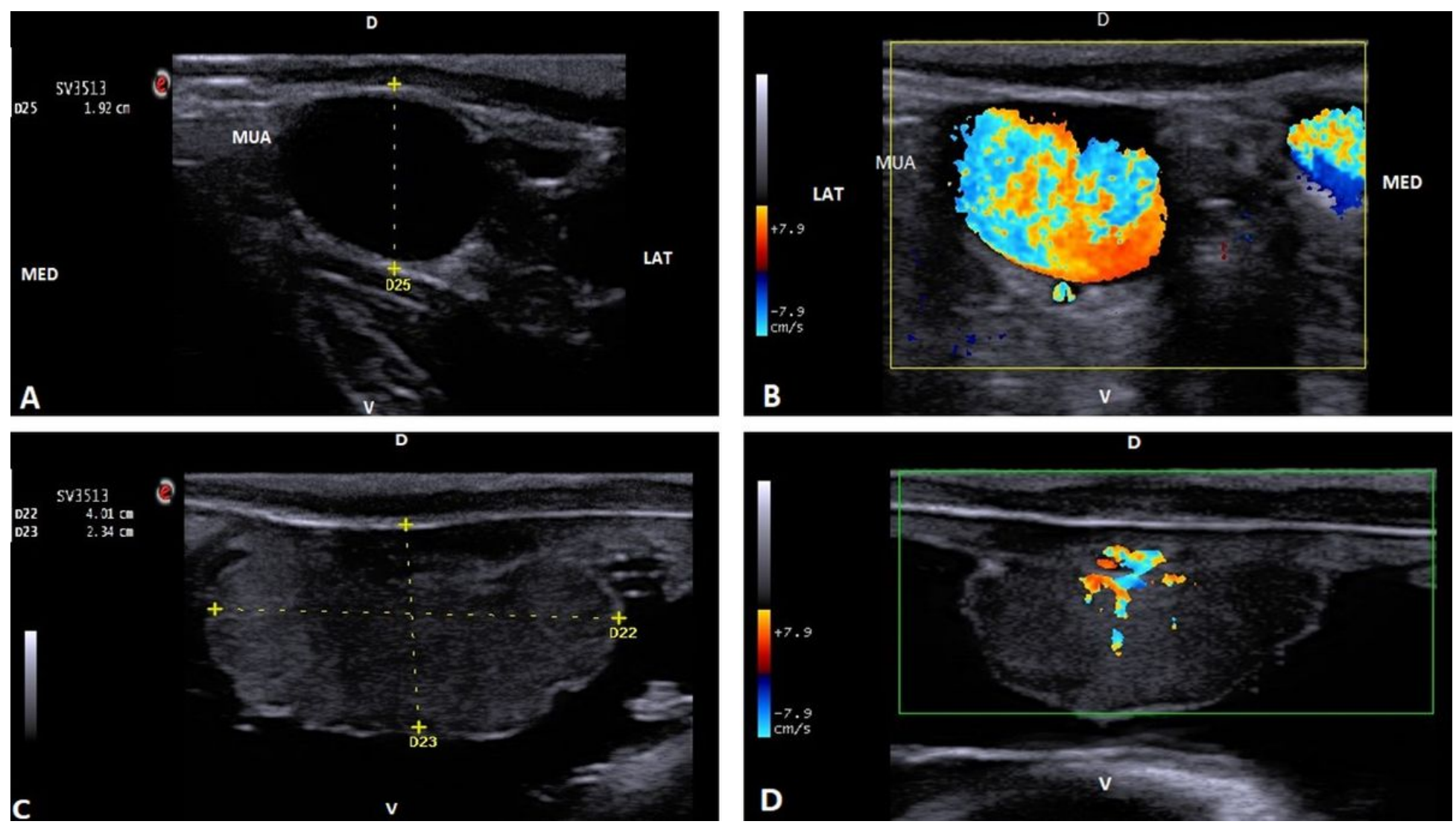

Figure 5

(A \&B): Ultrasonographic monitoring of middle uterine artery of heavy pregnant cows( $10 \mathrm{MHz}$ linear-array transrectal transducer $7 \mathrm{~cm}$ depth). (A): B-mode ultrasonography; (B): Doppler sonography. (C\&D): Ultrasonographic monitoring placentom of heavy pregnant dairy cows $(10 \mathrm{MHz}$ linear array transrectal transducer $7 \mathrm{~cm}$ depth). (C): B-mode ultrasonography; (D) Doppler sonography.

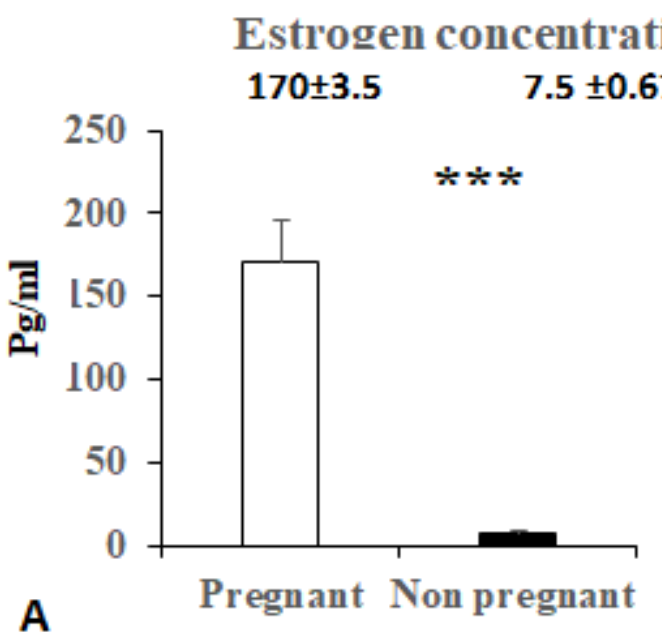

\section{Progestrone concentration}

$5.14 \pm 0.67 \quad 3.35 \pm 0.89$

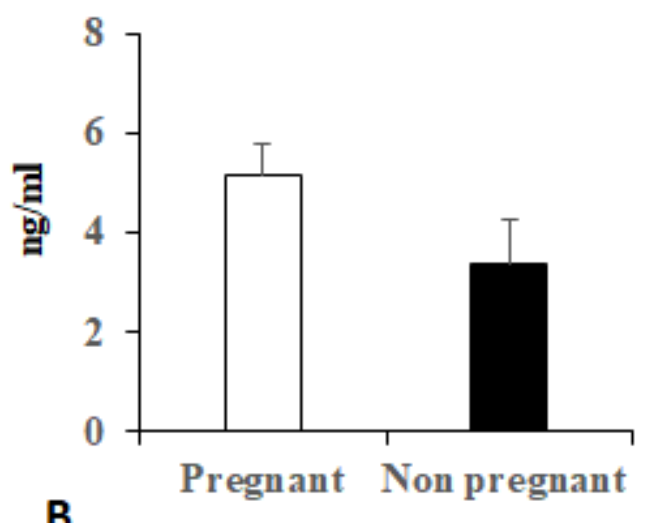

Figure 6 
Serum estrogen $(\mathrm{Pg} / \mathrm{ml})$ and progesterone $(\mathrm{ng} / \mathrm{ml})$ concentrations of heavy pregnant and non-pregnant dairy cows. Data are presented as mean \pm SE. *Values are significantly different between pregnant and non-pregnant cows 